\title{
Distribution of chlorine and fluorine in benthic foraminifera
}

\author{
Anne Roepert ${ }^{1}{ }^{\text {a }}$, Lubos Polerecky ${ }^{1}$, Esmee Geerken ${ }^{2}$, Gert-Jan Reichart ${ }^{1,2}$, and Jack J. Middelburg ${ }^{1}$ \\ ${ }^{1}$ Department of Earth Sciences, Utrecht University, P.O. Box 80021, 3508 TA Utrecht, the Netherlands \\ ${ }^{2}$ Department of Ocean Systems, NIOZ Royal Netherlands Institute for Sea Research, and Utrecht University, \\ 1790 AB Den Burg, the Netherlands \\ ${ }^{a}$ now at: Soil Chemistry and Chemical Soil Quality, Department of Environmental Sciences, Wageningen University, \\ P.O. Box 47, 6700 AA Wageningen, the Netherlands
}

Correspondence: Anne Roepert (anne.roepert@wur.nl)

Received: 22 October 2019 - Discussion started: 20 November 2019

Revised: 8 July 2020 - Accepted: 28 July 2020 - Published: 29 September 2020

\begin{abstract}
Over the last few decades, a suite of inorganic proxies based on foraminiferal calcite have been developed, some of which are now widely used for palaeoenvironmental reconstructions. Studies of foraminiferal shell chemistry have largely focused on cations and oxyanions, while much less is known about the incorporation of anions. The halogens fluoride and chloride are conservative in the ocean, which makes them candidates for reconstructing palaeoceanographic parameters. However, their potential as a palaeoproxy has hardly been explored, and fundamental insight into their incorporation is required. Here we used nanoscale secondary ion mass spectrometry (NanoSIMS) to investigate, for the first time, the distribution of $\mathrm{Cl}$ and $\mathrm{F}$ within shell walls of four benthic species of foraminifera. In the rotaliid species Ammonia tepida and Amphistegina lessonii, $\mathrm{Cl}$ and $\mathrm{F}$ were distributed highly heterogeneously within the shell walls, forming bands that were co-located with the bands observed in the distribution of phosphorus (significant positive correlation of both $\mathrm{Cl}$ and $\mathrm{F}$ with $\mathrm{P} ; p<$ 0.01). In the miliolid species Sorites marginalis and Archaias angulatus, the distribution of $\mathrm{Cl}$ and $\mathrm{F}$ was much more homogeneous without discernible bands. In these species, $\mathrm{Cl}$ and $\mathrm{P}$ were spatially positively correlated $(p<0.01)$, whereas no correlation was observed between $\mathrm{Cl}$ and $\mathrm{F}$ or between $\mathrm{F}$ and P. Additionally, their F content was about an order of magnitude higher than in the rotaliid species. The high variance in the $\mathrm{Cl}$ and $\mathrm{F}$ content in the studied foraminifera specimens could not be attributed to environmental parameters. Based on these findings, we suggest that $\mathrm{Cl}$ and $\mathrm{F}$ are predominately associated with organic linings in the rotaliid species. We further propose that $\mathrm{Cl}$ may be incorporated as a solid solution
\end{abstract}

of chlorapatite or may be associated with organic molecules in the calcite in the miliolid species. The high $\mathrm{F}$ content and the lack of a correlation between $\mathrm{Cl}$ and $\mathrm{F}$ or $\mathrm{P}$ in the miliolid foraminifera suggest a fundamentally different incorporation mechanism. Overall, our data clearly show that the calcification pathway employed by the studied foraminifera governs the incorporation and distribution of $\mathrm{Cl}, \mathrm{F}, \mathrm{P}$, and other elements in their calcite shells.

\section{Introduction}

Foraminifera are widely used to reconstruct palaeoenvironments and climates based on relative species abundances and the chemical or isotopic composition of their shells. Apart from the carbon and oxygen isotopic composition, most inorganic proxies based on foraminiferal calcite involve cations or their isotopes (Boyle, 1981; Elderfield et al., 1996; Lea et al., 1999; Allen et al., 2016), which can substitute for calcium in the calcite lattice. While there are also proxies based on the incorporation of oxyanions such as iodate, sulfate, borate, and their isotopes (Lu et al., 2010; Paris et al., 2014; Yu et al., 2007; Rae et al., 2011), much less is known about the incorporation of anions such as the halogens chloride, fluoride, and bromide that are less likely to substitute for the carbonate ion (Kitano et al., 1975; Okumura et al., 1983, 1986).

The halogen anions are conservative in the ocean, which makes them potential candidates for reconstructing palaeoceanographic parameters. Chlorine, as a major constituent of sea salt, is the most abundant halogen in seawater, followed by bromine, whereas fluorine concentrations are in the 
parts per million range (e.g. Kendrick, 2018, and references therein). However, even though $\mathrm{Cl}^{-}$is the most abundant (an)ion in seawater, the $\mathrm{Cl}$ content of inorganic and biogenic calcites is low because the $\mathrm{Cl}^{-}$anion does not fit well into the calcite lattice (Tokuyama et al., 1972; Kitano et al., 1975). In contrast, the $\mathrm{F}^{-}$anion has a much higher compatibility in many minerals compared with the heavier halogens, which can be attributed to its much smaller ionic radius (Kendrick, 2018). While seawater is enriched with the halogens chlorine and bromine with respect to the primary mantle (Kendrick, 2018), fluorine is strongly depleted in seawater, with calcium carbonates being the major sink of dissolved fluoride in the oceans (Carpenter, 1969).

Marine carbonates have $\mathrm{F} / \mathrm{Ca}$ ratios ranging between $0.1-$ 3.5 and $4.0-6.5 \mathrm{mmol} \mathrm{mol}^{-1}$ in calcite and aragonite respectively (Carpenter, 1969), whereas $\mathrm{Cl} / \mathrm{Ca}$ ratios range between 9-18 and 53-71 $\mathrm{mol} \mathrm{mol}^{-1}$ in inorganically precipitated calcite and aragonite respectively (Kitano et al., 1975). The fluorine content of planktic foraminifera covaries not only with $\delta^{18} \mathrm{O}$ (Rosenthal and Boyle, 1993; Opdyke et al., 1993; Rosenthal et al., 1997) but also with Mg and Sr content (Opdyke et al., 1993), and it mostly varies in response to species-specific biological factors (Rosenthal and Boyle, 1993; Opdyke et al., 1993; Rosenthal et al., 1997). Furthermore, the foraminiferal F content appears to be highly susceptible to diagenesis. Indeed, the release of $\mathrm{F}$ to porewater has been shown to be a proxy for carbonate dissolution during early diagenesis (Rude and Aller, 1991). The chlorine content of biogenic calcite has been proposed as a potential direct salinity proxy (Wit et al., 2013), but there are very few data on $\mathrm{Cl}$ in foraminifera (Szafranek and Erez, 1993; Erez, 2003).

Not much is known about how these anions are incorporated into foraminiferal shells. Possible incorporation modes include lattice-bound, interstitial, solid solution (e.g. fluorite, apatite), or bound to organic templates within the foraminiferal shell walls. Possible environmental factors playing a role during the incorporation processes of $\mathrm{Cl}$ and $\mathrm{F}$ may be related to $\mathrm{pH}$ homeostasis in the calcification fluid, as $\mathrm{Cl}^{-1}$ and $\mathrm{F}^{-1}$ are the dissociated compounds of a strong and weak acid respectively. Tanaka et al. (2013) showed that fluorine incorporation in non-symbiotic corals was governed by the carbonate ion concentration in solution because of ion-exchange between fluoride and carbonate. A similar link has been suggested between foraminiferal fluorine content and carbonate ion concentration (Rosenthal and Boyle, 1993; Opdyke et al., 1993) as well as the presence of symbionts (Opdyke et al., 1993).

Furthermore, the spatial distribution of incorporated elements within foraminiferal shells can shed light on the incorporation mechanism. To the best of our knowledge, the spatial distribution of $\mathrm{F}$ has not been investigated yet, whereas $\mathrm{Cl}$ has previously been found at the location of organic linings in shell walls of A. lobifera (Szafranek and Erez, 1993; Erez, 2003). Recently, the iodine micro-distribution in shell walls of Uvigerina striata was also found to spatially correlate with organics (Glock et al., 2019). This suggests that halogen incorporation may be regulated by foraminiferal biomineralization pathways, although biogenic carbonate formation is ultimately expected to be governed by the same controlling factors as inorganic carbonate formation. The biomineralization pathway has consequences for trace element incorporation, as reflected in the occurrence of bands of higher and lower concentrations of cations (e.g. $\mathrm{Mg}, \mathrm{Sr}, \mathrm{Ba}, \mathrm{Na}$ ) in perforate hyaline foraminiferal shell walls (Eggins et al., 2004; Sadekov et al., 2005; Kunioka et al., 2006; Branson et al., 2015; Jonkers et al., 2016; Geerken et al., 2018, 2019). This banding has been attributed to chamber addition in perforate hyaline foraminifera: an additional high-concentration band appears each time a new calcite lamella is added to the shell, which also covers previous chambers (Nehrke et al., 2013). Similarly, spines of planktic foraminifera are enriched in $\mathrm{Na}$ and depleted in $\mathrm{Mg}$, whereas the spine attachment zones are depleted in $\mathrm{Na}$ and enriched in $\mathrm{Mg}$ (Branson et al., 2016; Mezger et al., 2019; Bonnin et al., 2019).

Here we investigated, for the first time, the $\mathrm{Cl}$ and $\mathrm{F}$ distribution within foraminiferal shell walls of four benthic species at the submicron scale using NanoSIMS. Two rotaliid (hyaline) benthic species (Ammonia tepida and Amphistegina lessonii) and two miliolid (porcellaneous) benthic species (Sorites marginalis and Archaias angulatus) were investigated to cover benthic foraminifera with fundamentally different biomineralization pathways. Furthermore, one species is a symbiont-barren species (Ammonia tepida), whereas the other three species bear photosynthetic symbionts.

\section{Materials and methods}

\subsection{Specimen selection and basic characterization}

Six specimens from four species (two rotaliid and two miliolid species) from culturing experiments were investigated in this study (Table 1). The use of laboratory-grown specimens has the advantage that their growth conditions have been controlled and that potential effects of diagenesis on their shell halogen chemistry can be excluded. The A. angulatus and $S$. marginalis specimens were collected in Sint Eustatius (Oranjestad Bay; $17.479751^{\circ} \mathrm{N}-62.987273^{\circ} \mathrm{W}$ ). The culture experiments with $A$. angulatus and $S$. marginalis were conducted in the same manner as described in van Dijk et al. (2017), with the exception of media preparation. Culture media of different salinities were prepared by mixing natural $0.2 \mu \mathrm{m}$ filtered seawater with deionized water and "instant ocean" salt in order to obtain a range of salinities between 25 and 45. Calcein was added during the course of the experiment, and fluorescence images were used to identify newly precipitated calcite. The A. lessonii specimens are from Burger's Zoo in the Netherlands (van Dijk et al., 2019), and the culture conditions are reported in van Dijk et al. 
(2019). The specimens of A. tepida were collected on a tidal flat near Den Oever, the Wadden Sea, in the Netherlands, and the culture conditions are described in Geerken et al. (2018). For both the cultures of A. lessonii and A. tepida, two to three chambered juveniles were transferred into Petri dishes containing culture media with adjusted salinity and alkalinity, where the specimens precipitated additional chambers. Prior to embedding, all specimens were cleaned using an adapted Barker protocol (Barker et al., 2003), only applying the organic removal/oxidation step, in which $\mathrm{NaOH}$ was replaced by $\mathrm{NH}_{4} \mathrm{OH}$, as described in detail in Geerken et al. (2018). During the culture experiments there were no visual indicators of the inorganic precipitation of calcite. Moreover, scanning electron microscope (SEM) inspection of the measured specimens showed no inorganic calcite overgrowth.

Parameters of the carbonate system in the culture media stock, including the alkalinity, carbonate ion concentration, and saturation state with respect to calcite, were calculated from the measured dissolved inorganic carbon (DIC) concentration, $\mathrm{pH}$, salinity, and temperature (Table 1); this was done in R (R Core Team, 2018) using the seacarb package (Gattuso et al., 2018). The equilibrium constants for the carbonate system $K_{1}$ and $K_{2}$ were taken from Lueker et al. (2000). Because DIC was not measured in the culture of A. lessonii, we first applied the salinity-alkalinity relationship for the North Atlantic (Lee et al., 2006) to estimate the culture medium alkalinity; based on this value, we then calculated the remaining carbonate system parameters. The concentrations of $\mathrm{Cl}$ and $\mathrm{F}$ in the culture media were not directly determined. However, as $\mathrm{Cl}$ and $\mathrm{F}$ are conservative elements following salinity, the concentrations are expected to resemble those in sea water with the same salinity. Due to the small culturing volumes (Petri dishes), the parameters of the media could not be monitored during the experiments. However, potential changes due to evaporation during feeding or cleaning of the cultures are expected to be negligible, because the culture media were regularly renewed (twice a week), when compared with the large differences between the treatments.

Prior to sample preparation for NanoSIMS analyses, each specimen was characterized with respect to its $\mathrm{Na}, \mathrm{Mg}, \mathrm{Sr}$, and $\mathrm{Ba}$ content. This was done by laser ablation inductively coupled plasma mass spectrometry (LA-ICP-MS) for A. tepida and A. lessonii as previously described (Geerken et al., 2018; van Dijk et al., 2019). For $A$. angulatus and $S$. marginalis LA-ICP-MS analyses were performed using the same methodology as described in Geerken et al. (2018). For each specimen element-to-calcium $(\mathrm{El} / \mathrm{Ca})$ ratios were determined on two or more chambers and were averaged (Table A1 in Appendix A).

\subsection{Sample preparation and SEM imaging}

The selected specimens of A. tepida, A. lessonii, $S$. marginalis, and $A$. angulatus were embedded in epoxy resin (Araldite 2020) under vacuum and subsequently polished to expose cross sections perpendicular to the shell walls (see Geerken et al. (2019) for details). Although epoxy resins contain high amounts of chlorine, we are confident that the halogens measured in the foraminiferal calcite are not due to contamination with resin nor are they an artefact of redeposition during the sputtering process (Roepert, 2019a). The first polishing steps used wet grinding papers of decreasing coarseness (HERMES, WS Flex 18C, $230 \mathrm{~mm}, \mathrm{P}$ 800, and 219 ATM, SiC wet grinding paper, grain 4000) followed by agglomerated alpha alumina powder (Struers AP-A powder, grain size $0.3 \mu \mathrm{m}$ ) and $\mathrm{SiO}_{2}$ powder (Logitech SF1 Polishing Suspension, grain size $0.035 \mu \mathrm{m}$ ). The polished samples underwent sputter coating with $20 \mathrm{~nm}$ of Au using a sputter coater (JEOL JFC-2300HR high-resolution fine coater with JEOL FC-TM20 thickness controller), after which they were imaged using a JEOL Neoscope II JCM-6000 benchtop SEM to identify suitable areas for NanoSIMS analysis (Fig. A1 in Appendix A).

\subsection{NanoSIMS imaging}

The fields of view for NanoSIMS imaging were carefully selected using SEM images on the basis of the position in the specimen and the quality of the surface preparation. Where possible, distal chambers were measured, but more proximal chambers were preferred if their cross-sectional surfaces appeared flatter or cleaner. NanoSIMS analysis was performed with the CAMECA NanoSIMS 50L instrument available at Utrecht University. Using an element standard (SPI Supplies, 02757-AB 59 Metals and Minerals Standard), the magnetic field and exact positions of the electron multiplier detectors were adjusted to enable the detection of negative secondary ions ${ }^{12} \mathrm{C}^{-},{ }^{16} \mathrm{O}^{-},{ }^{19} \mathrm{~F}^{-},{ }^{31} \mathrm{P}^{-},{ }^{35} \mathrm{Cl}^{-},{ }^{37} \mathrm{Cl}^{-}$, and ${ }^{40} \mathrm{Ca}^{16} \mathrm{O}^{-}$. The secondary ions were sputtered from the sample surface using an $8 \mathrm{kV}$ primary $\mathrm{Cs}^{+}$ion source.

Because the primary ion beam was positive, calcium had to be detected as ${ }^{40} \mathrm{Ca}^{16} \mathrm{O}^{-}$and not as ${ }^{40} \mathrm{Ca}^{+}$. However, because the $\mathrm{Ca}: \mathrm{O}$ stoichiometry in calcite with trace amounts of organics is fixed, we assumed that the measured distribution of ${ }^{40} \mathrm{Ca}^{16} \mathrm{O}$ approximated the distribution of $\mathrm{Ca}$ well. This assumption was supported by the good correlation between the secondary ions ${ }^{40} \mathrm{Ca}^{16} \mathrm{O}^{-}$and ${ }^{16} \mathrm{O}^{-}$detected from the calcite (Fig. A2). ${ }^{31} \mathrm{P}$ was measured as a tracer for organics in the calcite (Geerken et al., 2019), whereas ${ }^{12} \mathrm{C}$ was measured to help distinguish between resin and calcite. To ensure that the detection of ${ }^{35} \mathrm{Cl}$ was not influenced by possible isobaric interferences such as ${ }^{16} \mathrm{O}^{18} \mathrm{O}^{1} \mathrm{H}$ and ${ }^{34} \mathrm{~S}^{1} \mathrm{H}$, we used sufficiently high mass resolving power (MRP; MRP > 5113) and additionally also measured the isotope ${ }^{37} \mathrm{Cl}$. The obtained ${ }^{37} \mathrm{Cl} /{ }^{35} \mathrm{Cl}$ ratio differed from the natural abundance ratio of 0.320 by no more than 0.015 , confirming that the influence of isobaric interferences for the detection of $\mathrm{Cl}$ was negligible. Similarly, the separation of ${ }^{19} \mathrm{~F}$ from possible interference by ${ }^{18} \mathrm{O}^{1} \mathrm{H}$ was achieved by using 
Table 1. The foraminifera specimens studied and the corresponding culture conditions.

\begin{tabular}{llrrrrrrr}
\hline No. & Species & Salinity & $T\left({ }^{\circ} \mathrm{C}\right)$ & $\begin{array}{r}\text { DIC } \\
\left(\mu \mathrm{mol} \mathrm{kg}{ }^{-1}\right)\end{array}$ & $\begin{array}{r}\text { Alkalinity } \\
\left(\mu \mathrm{mol} \mathrm{kg}{ }^{-1}\right)\end{array}$ & $\mathrm{pH}$ & $\begin{array}{r}\mathrm{CO}_{3}^{2-} \\
\left(\mu \mathrm{mol} \mathrm{kg}^{-1}\right)\end{array}$ & $\Omega_{\text {calcite }}$ \\
\hline $1^{\mathrm{b}}$ & A. tepida $(\mathrm{R})$ & 25.2 & 25 & 1087 & 1350 & 8.32 & 162 & 4.22 \\
$2^{\mathrm{c}}$ & A. lessonii $(\mathrm{R})$ & 35.2 & 21.2 & 2069 & 2314 & 8.00 & 177 & 4.24 \\
$3^{\mathrm{d}}$ & A. angulatus (M) & 40 & 25 & 3861 & 4477 & 8.10 & 506 & 11.67 \\
$4^{\mathrm{d}}$ & A. angulatus (M) & 30 & 25 & 2644 & 3153 & 8.27 & 399 & 10.00 \\
$5^{\mathrm{d}}$ & S. marginalis (M) & 30 & 25 & 2644 & 3153 & 8.27 & 399 & 10.00 \\
$6^{\mathrm{d}}$ & S. marginalis (M) & 40 & 25 & 3861 & 4477 & 8.10 & 506 & 11.67 \\
\hline
\end{tabular}

${ }^{a} \mathrm{R}$ refers to rotaliid, and $\mathrm{M}$ refers to miliolid. ${ }^{\mathrm{b}}$ Selected from the culture experiment of Geerken et al. (2018). ${ }^{\mathrm{c}}$ Selected from the culture experiment of van Dijk et al. (2019). ${ }^{d}$ Selected from an unpublished culture experiment (see details in the text).

MRP > 2214, whereas interferences from molecules such as ${ }^{12} \mathrm{C}^{7} \mathrm{Li},{ }^{13} \mathrm{C}^{6} \mathrm{Li}$, or ${ }^{16} \mathrm{O}^{1} \mathrm{H}_{3}$ are highly unlikely.

Before each analysis, the area of interest was pre-sputtered for 10-15 min until secondary ion counts stabilized. Subsequently, ion count images were acquired by rastering the primary beam (dwell time of $1 \mathrm{~ms} \mathrm{px}^{-1}$ ) over the sample surface using the diaphragm and slit settings listed in Table A2. The primary beam current on the sample surface ranged between 0.5 and $2 \mathrm{pA}$ depending on the size of the imaged area. The spatial resolution ranged between 50 and $100 \mathrm{~nm} \mathrm{px}^{-1}$. All analyses employed an eGun to avoid charging of the sample surface. Because some of the secondary ion counts were very low, the imaged areas were measured multiple times (2501000 , depending on the sample), and the signals from the individual planes were aligned and accumulated.

\subsection{Data processing}

NanoSIMS data were processed with the Look@NanoSIMS freeware program (Polerecky et al., 2012). After alignment and accumulation of the image data, regions of interest (ROIs) corresponding to foraminiferal calcite were drawn by hand based on the ${ }^{40} \mathrm{Ca}^{16} \mathrm{O}^{-}$image. With the additional use of the ${ }^{12} \mathrm{C}^{-}$and ${ }^{35} \mathrm{Cl}^{-}$images, areas of exposed resin or pores within the foraminiferal walls were identified and excluded from the final analysis.

Due to the lack of reliable calibration standards and because $\mathrm{Ca}$ was measured as the molecular ion ${ }^{40} \mathrm{Ca}^{16} \mathrm{O}^{-}$, the $\mathrm{El} / \mathrm{Ca}$ ratios are reported in this study by the ratios between the raw data, i.e. the secondary ion counts $\mathrm{El}^{-}$and ${ }^{40} \mathrm{Ca}^{16} \mathrm{O}^{-}$. Although not fully quantitative, the ratios calculated in this way are comparable between the different foraminifera specimens and species because the secondary ion counts detected by NanoSIMS are linearly proportional to the concentration of the corresponding element, and because all of the measurements were done in a similar biogenic calcite matrix using the same pre-sputtering and measuring protocol.

To ensure that the El/Ca ratios were not affected by insufficient pre-sputtering, depth profiles of the $\mathrm{El}^{-} /{ }^{40} \mathrm{Ca}^{16} \mathrm{O}^{-}$ ion count ratios were inspected for each ROI, and the planes where the ratios showed a significant trend with depth were excluded from the final analysis. Lateral profiles of the $\mathrm{El}^{-} /{ }^{40} \mathrm{Ca}^{16} \mathrm{O}^{-}$ion count ratios perpendicular to the shell surface were extracted from the accumulated NanoSIMS images. The width of the profile line, which corresponds to the amount of averaged lateral profiles, was set to $20 \mathrm{px}$ to increase the signal-to-noise ratio. As such, lateral profiles that cover a representative fraction of a shell wall may be comparable to LA-ICP-MS profiles, albeit with a higher resolution.

To investigate the spatial correlation of $\mathrm{El}^{-} /{ }^{40} \mathrm{Ca}^{16} \mathrm{O}^{-}$ion count ratios, ROIs were drawn on the NanoSIMS images in Look@NanoSIMS in such a way that regions of higher and lower ion count ratios on the foraminifera were separated into different ROIs to separate the spatial variability. Thus, 40 to 47 separate data points (ROIs) per species, grouped per specimen, were extracted from the NanoSIMS images. Subsequently, correlation matrices were calculated for the accumulated ion count ratios in those ROIs using the corrplot package (Wei and Simko, 2017) in R (R Core Team, 2018).

\section{Results}

\subsection{Spatial distribution of chlorine and fluorine}

The halogens $\mathrm{Cl}$ and $\mathrm{F}$ show distinct banding in the rotaliids, in particular in A.tepida (Fig. 1). These bands are not caused by lower $\mathrm{Ca}$ intensities at these locations (Fig. A6). Moreover, in the rotaliids, maxima of $\mathrm{Cl} / \mathrm{Ca}$ and $\mathrm{F} / \mathrm{Ca}$ are co-located with those of $\mathrm{P} / \mathrm{Ca}$ and correlate well in $\mathrm{A}$. tepida, while the correspondence between $\mathrm{P} / \mathrm{Ca}$ and $\mathrm{F} / \mathrm{Ca}$ is moderate in $A$. lessonii and spatially rather complex for $\mathrm{Cl} / \mathrm{Ca}$ (see lateral profiles in Fig. 1). Furthermore, the contrast between the high-intensity and low-intensity bands in $\mathrm{F} / \mathrm{Ca}, \mathrm{Cl} / \mathrm{Ca}$, and $\mathrm{P} / \mathrm{Ca}$ is higher in $A$. tepida than in A. lessonii. In the miliolid foraminifers no banding of halogens nor $\mathrm{P}$ is visible, with the exception of a slight elevation in $\mathrm{Cl}$ and $\mathrm{P}$ in areas of an image that were identified as a suture in the SEM images. Lateral profiles in A. angulatus show a correlation of $\mathrm{Cl}$ with $\mathrm{P}$ and no correlation of $\mathrm{F}$ with $\mathrm{Cl}$ or $\mathrm{P}$. The lateral 
profile through the shell wall of $S$. marginalis shows similar patterns to the one of $A$. angulatus. The $\mathrm{F} / \mathrm{Ca}$ ion count ratios in the miliolids A. angulatus and S. marginalis are in the same range and are 1 order of magnitude higher than those in the rotaliids A. tepida and A. lessonii (Figs. 1, 2). The $\mathrm{Cl} / \mathrm{Ca}$ and $\mathrm{P} / \mathrm{Ca}$ ion count ratios are of the same order of magnitude in all four species (Figs. 1, 2).

Ion count ratios of $\mathrm{F} / \mathrm{Ca}$ and $\mathrm{Cl} / \mathrm{Ca}$ correlate with each other in A. tepida, whereas there is no correlation in $A$. lessonii and the miliolids (Figs. 2a, A3). Both F/Ca and $\mathrm{Cl} / \mathrm{Ca}$ are correlated with $\mathrm{P} / \mathrm{Ca}$ in the rotaliids, whereas only $\mathrm{Cl} / \mathrm{Ca}$ is correlated with $\mathrm{P} / \mathrm{Ca}$ in the miliolids (Fig. 2b, c). All correlations described here are significant at the $p<$ 0.001 level; $R^{2}$ and $p$ values of the correlations are reported in Fig. A3. These correlations are also seen when the elements $\mathrm{F}, \mathrm{Cl}$, and $\mathrm{P}$ are normalized to $\mathrm{O}$ instead being normalized to $\mathrm{Ca}$ (Fig. A5).

\subsection{Relation to cation incorporation and culture media properties}

In all four species, the $\mathrm{Cl}$ content does not correlate with any of the elemental ratios measured by LA-ICP-MS (upper panels in Fig. 3). However, the elevated F/Ca ratios in the miliolid foraminifera coincide with elevated $\mathrm{Mg} / \mathrm{Ca}$ and $\mathrm{Ba} / \mathrm{Ca}$, which also are an order of magnitude higher in these species than in the rotaliid foraminifera (lower panels in Fig. 3). Our data show no correlation of $\mathrm{Cl} / \mathrm{Ca}$ or $\mathrm{F} / \mathrm{Ca}$ with $\mathrm{Na} / \mathrm{Ca}$ nor with $\mathrm{Sr} / \mathrm{Ca}$ (Fig. 3).

Our data show no correlation of $\mathrm{Cl} / \mathrm{Ca}$ or $\mathrm{F} / \mathrm{Ca}$ with salinity or temperature (Fig. A4). Furthermore, cross plots of the NanoSIMS $\mathrm{Cl} / \mathrm{Ca}$ and $\mathrm{F} / \mathrm{Ca}$ ion count ratios show no correlation with carbonate system parameters for $\mathrm{Cl} / \mathrm{Ca}$ (Fig. 4). However, NanoSIMS F/Ca ion count ratios are higher in the miliolid foraminifera, which were cultured at a higher DIC, corresponding to higher alkalinity and carbonate ion concentration (Fig. 4).

\section{Discussion}

\subsection{Limited environmental control on $\mathrm{Cl}$ and $\mathrm{F}$ incorporation into foraminiferal shells}

The NanoSIMS data presented clearly show that biomineralization pathways govern the incorporation and distribution of $\mathrm{Cl}$ and $\mathrm{F}$ within foraminiferal shells: the rotaliid species show distinct banding in $\mathrm{Cl}, \mathrm{F}$, and $\mathrm{P}$, whereas the F-rich miliolid species do not. Biologic control is known to affect the incorporation of most elements into foraminiferal shells, while relationships with environmental conditions have also proven to be robust tools for palaeo-reconstructions (Eggins et al., 2004; Kunioka et al., 2006; Paris et al., 2014; Spero et al., 2015; Fehrenbacher et al., 2017; Geerken et al., 2019). In our data set, which is comprised of a very limited number of specimens, we see no overall trend in $\mathrm{Cl} / \mathrm{Ca}$ ratios in foraminiferal calcite with chemical properties of the culture media. The high intra-shell variability in rotaliid foraminifera and the spatial correlation with $\mathrm{P}$ on the location of organic linings suggest that $\mathrm{Cl}$ is associated with organic linings in rotaliid foraminiferal shells. Furthermore, $\mathrm{Cl} / \mathrm{Ca}$ is highly variable within a single section through a foraminiferal wall in all the species measured, and the range of $\mathrm{Cl} / \mathrm{Ca}$ ratios is similar in all investigated specimens.

The overall absence of trends with environmental conditions as well as the high intra-specimen variability lowers the confidence in potentially using $\mathrm{Cl} / \mathrm{Ca}$ for palaeoreconstructions. However, as this study does not cover a range of physicochemical parameters for a single species but rather presents a collection of a limited number of specimens of different species that were also grown under different conditions, we cannot exclude that any of the presented physicochemical parameters may exert an influence on the $\mathrm{Cl}$ content of foraminifera on a species-specific level. We emphasize that a definite conclusion regarding proxy applicability would require culturing studies including 20-30 specimens per species per environmental condition.

Moreover, there is no discernable trend of $\mathrm{Cl} / \mathrm{Ca}$ ratios in foraminiferal calcite with any of the measured trace elements (Fig. 3). $\mathrm{Cl} / \mathrm{Ca}$ ratios are in the same range for species with low-Mg calcite (rotaliid) as they are for those with highMg calcite (miliolid), suggesting that chlorine incorporation is systematically different from the incorporation of these cations. In inorganically precipitated calcite, chlorine contents are an order of magnitude lower than sodium contents (Kitano et al., 1975), suggesting that $\mathrm{Cl}$ is not incorporated as fluid inclusions (Wit et al., 2013) nor as solid solutions of $\mathrm{NaCl}$ into calcite. As the chlorine content seems not to reflect any environmental parameter and $\mathrm{Cl} / \mathrm{Ca}$ correlates well with $\mathrm{P} / \mathrm{Ca}$ in all the species investigated here, we suspect that chlorine incorporation into foraminiferal calcite is closely related to organic molecules involved in calcification. Another possibility may be a solid solution between calcite and a mineral containing both $\mathrm{Cl}$ and $\mathrm{P}$, such as chlorapatite $\left(\mathrm{Ca}_{5}\left(\mathrm{PO}_{4}\right)_{3}(\mathrm{OH}, \mathrm{Cl})\right)$. As NanoSIMS cannot distinguish between the these options, further research involving spectroscopic techniques is required to elucidate the nature of $\mathrm{Cl}$ incorporation in calcite.

The $\mathrm{F} / \mathrm{Ca}$ ratios in the miliolid species are about an order of magnitude higher than those in the rotaliid species. The elevated $\mathrm{F} / \mathrm{Ca}$ ratios in miliolids coincide with an overall higher $\mathrm{CO}_{3}^{2-}$ ion concentration in the culture media of the miliolid species. This might indicate a relation between foraminiferal $\mathrm{F} / \mathrm{Ca}$ ratios and carbonate ions, but the relationship is the inverse of what one would expect for inorganic ion exchange (Ichikuni, 1979) and what has been observed in corals (Tanaka et al., 2013). However, the high intra-shell variability in the $\mathrm{F} / \mathrm{Ca}$ ratios of single specimens and the covariation of environmental conditions with mineralization pathway complicates attributing $\mathrm{F} / \mathrm{Ca}$ ratios to environmental parameters. Species-specific culturing studies 

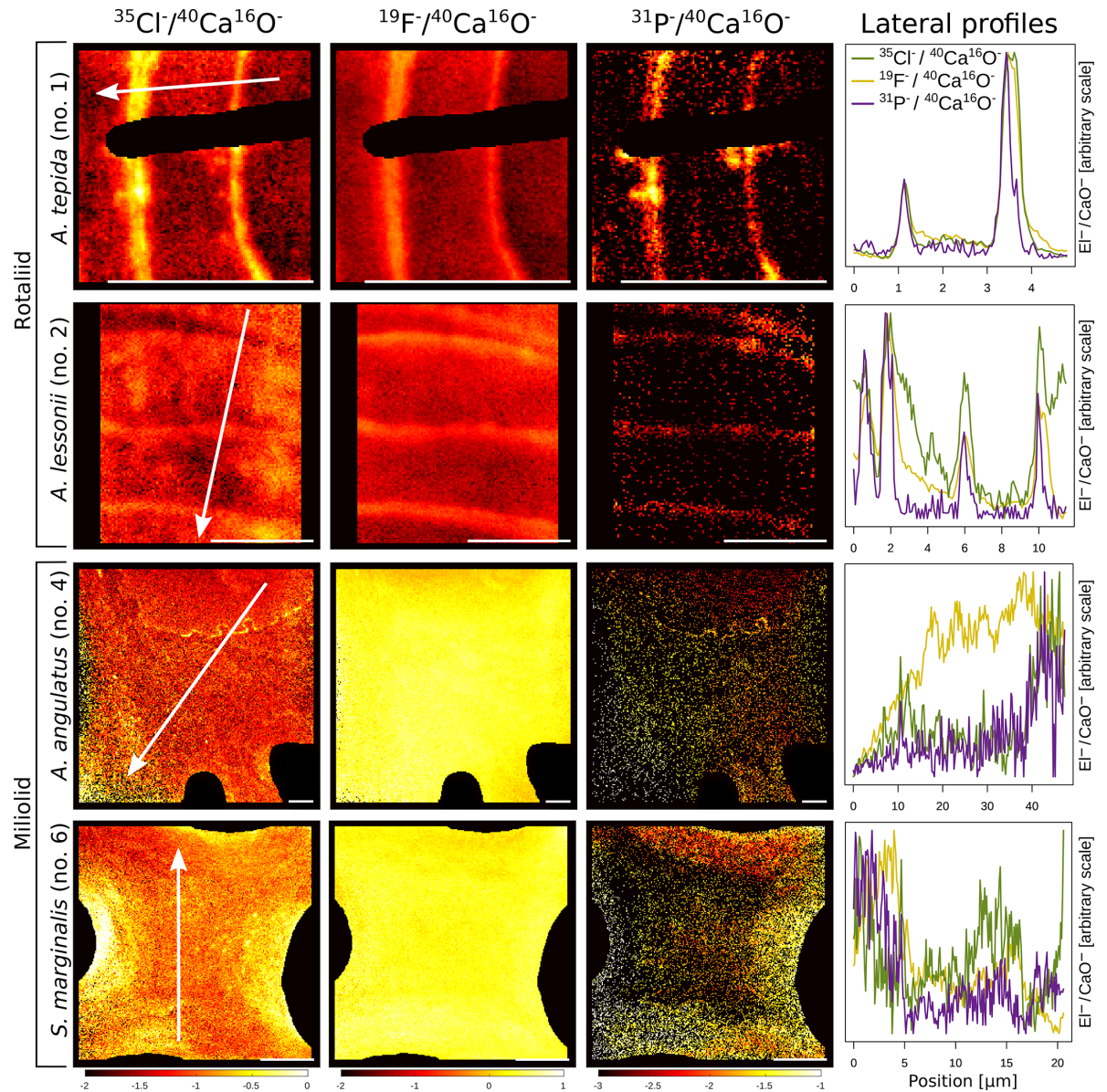

Figure 1. Spatial distribution of $\mathrm{Cl} / \mathrm{Ca}, \mathrm{F} / \mathrm{Ca}$, and $\mathrm{P} / \mathrm{Ca}$ ion count ratios in the calcite shells of the studied foraminifera species. Shown are representative images as well as lateral profiles along a line going from the inside to the outside of the shell, as depicted by an arrow in the images. Note that the displayed ratio images are log transformed and that the colour scale for the given ratio is the same for all species. Blacked out areas correspond to resin. The scale bar in each image is $5 \mu \mathrm{m}$. Details on the culturing conditions of these specimens are provided in Table 1. Locations of the NanoSIMS images within the shells are shown in Fig. A1.
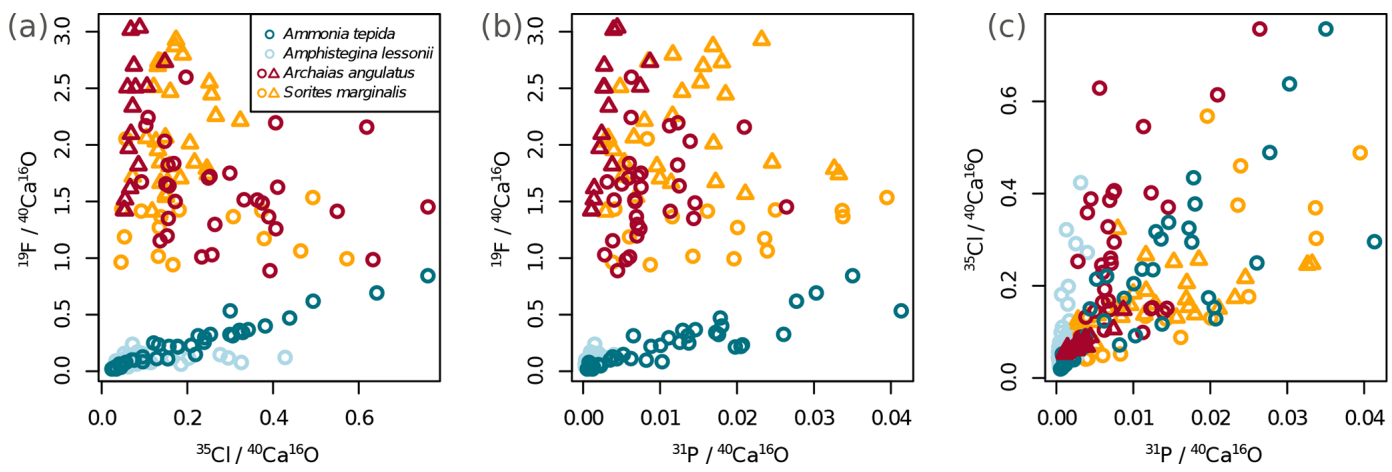

Figure 2. Variability of the different $\mathrm{El} / \mathrm{Ca}$ ratios within shells of the studied foraminifera. Individual data points represent multiple regions of interest (ROIs) drawn on the images as described in Sect. 2.4. Values are shown as ratios of secondary ion counts measured by NanoSIMS. Symbol shapes that are the same colour depict different specimens of the same species. 

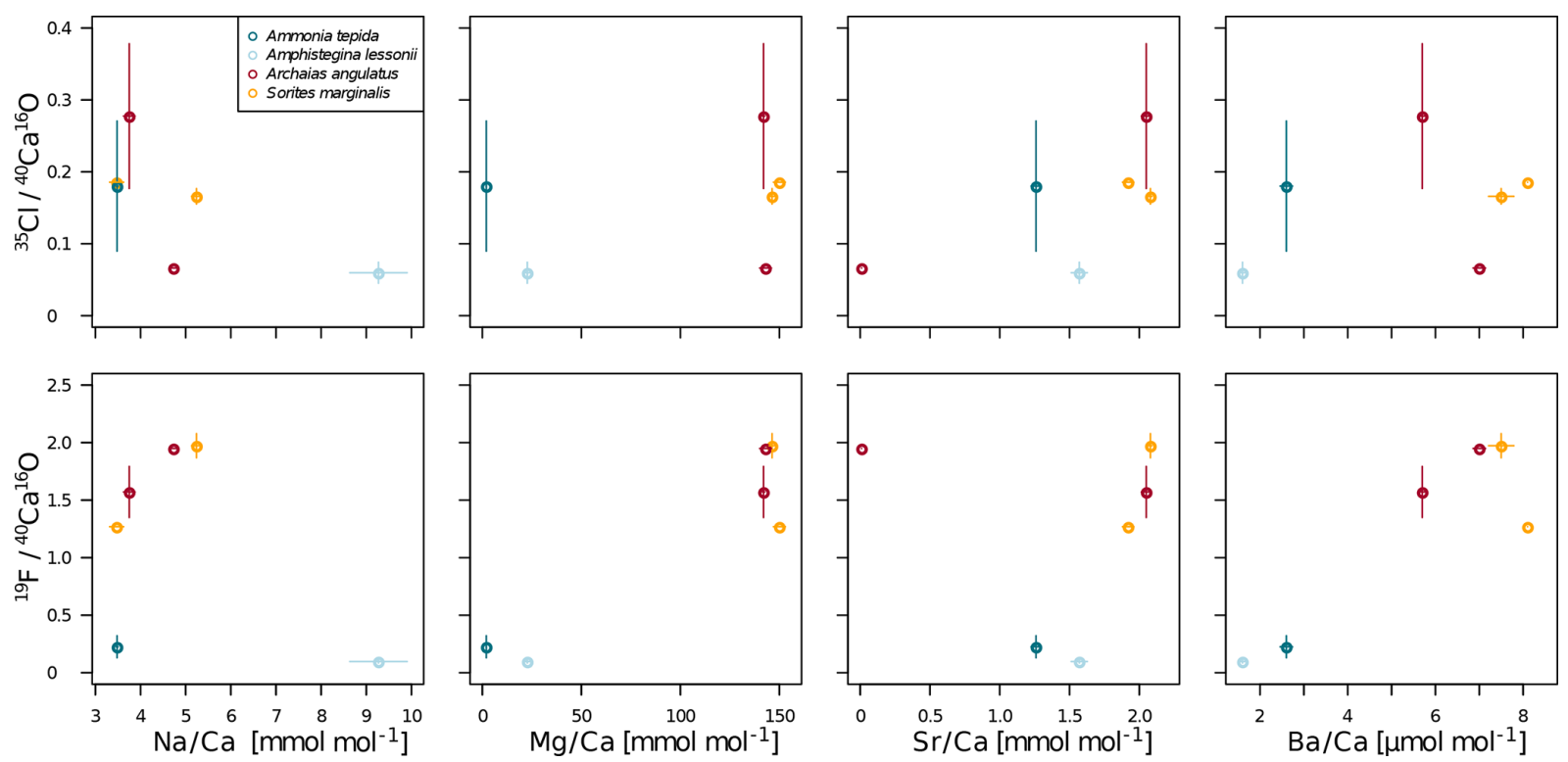

Figure 3. Cross plots of NanoSIMS ${ }^{35} \mathrm{Cl} /{ }^{40} \mathrm{Ca}^{16} \mathrm{O}$ and ${ }^{19} \mathrm{~F} /{ }^{40} \mathrm{Ca}{ }^{16} \mathrm{O}$ ion count ratios with LA-ICP-MS El/Ca ratios in the same specimen. The error bars depict 1 standard error of the mean NanoSIMS ion count ratios where more than one image was analysed per specimen and 1 standard error of duplicate or triplicate LA-ICP-MS measurements. The calculation of correlations was not attempted due to the low number of replicate measurements.
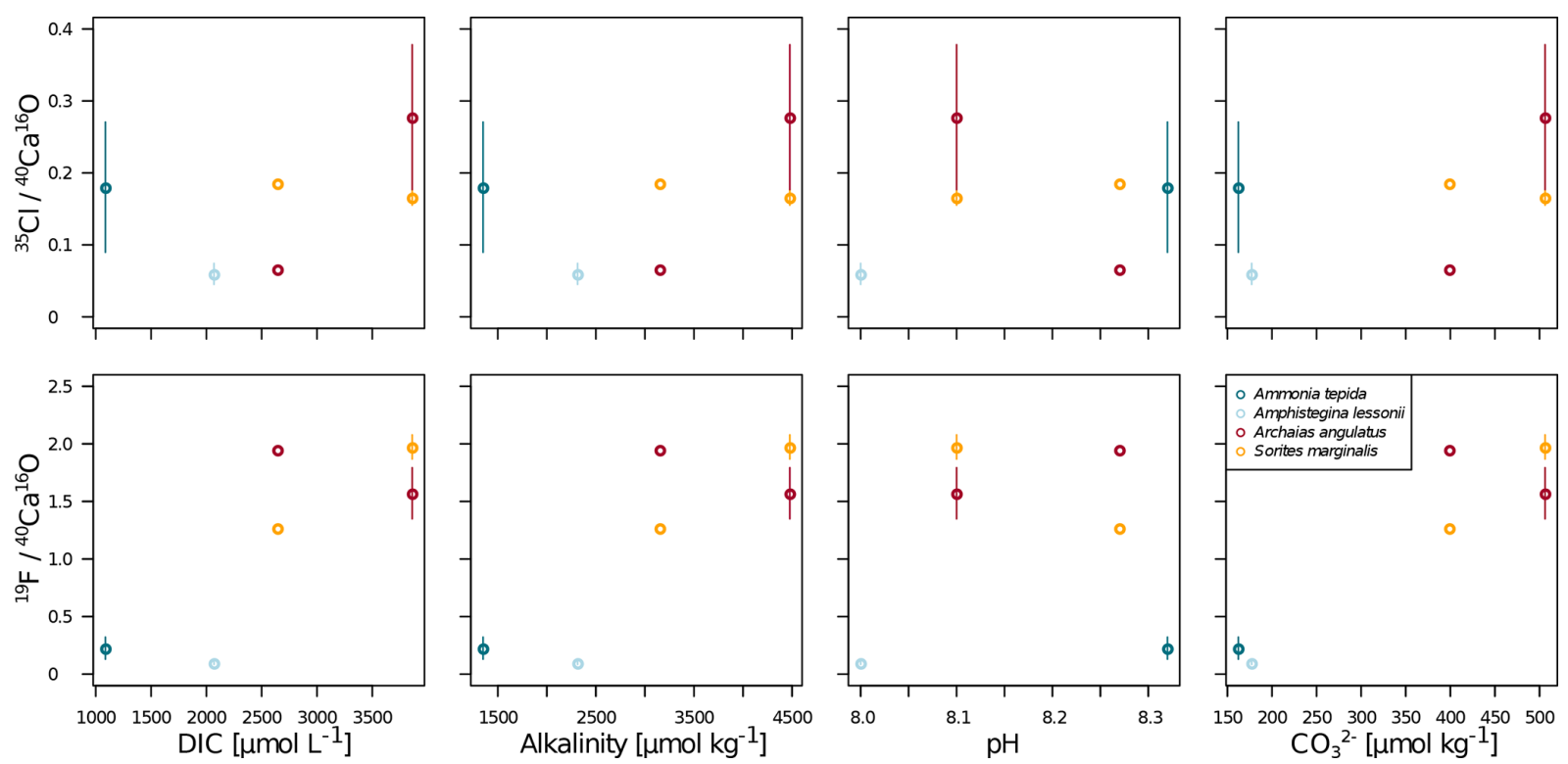

Figure 4. Cross plots of NanoSIMS ${ }^{35} \mathrm{Cl} /{ }^{40} \mathrm{Ca}{ }^{16} \mathrm{O}$ and ${ }^{19} \mathrm{~F} /{ }^{40} \mathrm{Ca}^{16} \mathrm{O}$ ion count ratios with carbonate system parameters of the culture media. The error bars depict 1 standard error of the mean NanoSIMS ion count ratios where more than one image was analysed per specimen. The calculation of correlations was not attempted due to the low number of replicate measurements.

could provide more insight into whether $\mathrm{F} / \mathrm{Ca}$ ratios of benthic foraminifera on a species-specific level correlate with environmental conditions, as the effect of different biomineralization pathways would then not hamper interpretation as is the case in our data set.

Opdyke et al. (1993) suggested that the presence of photosynthetic symbionts in foraminifera impacts their $\mathrm{F} / \mathrm{Ca}$ ra- tio. Symbionts influence the intracellular carbonate chemistry by photosynthesis, which could link to fluoride incorporation via the intracellular $\mathrm{CO}_{3}^{2-}$ ion activity. A. tepida is the only symbiont-barren species that we investigated, and its $\mathrm{F} / \mathrm{Ca}$ ratios are indeed lower than in the miliolid symbiontbearing species. However, the symbiont-bearing rotaliid $A$. lessonii exhibits the lowest mean $\mathrm{F} / \mathrm{Ca}$ ratios, which are of 
the same order of magnitude as in A. tepida but are less variable throughout the shell wall. Therefore, we conclude that the $\mathrm{F} / \mathrm{Ca}$ ratio is unlikely directly related to the presence of symbionts in foraminifera.

Notably, F/Ca ratios are higher in specimens with a higher $\mathrm{Mg}$ and Ba content (Fig. 3). A correlation of trace element content with $\mathrm{Mg}$ content within and between species has been found for several elements, including $\mathrm{Sr}, \mathrm{Zn}$, and $\mathrm{Na}$ (Evans et al., 2015; van Dijk et al., 2017; Geerken et al., 2018), and also F (Opdyke et al., 1993). The miliolid species generally have a much higher $\mathrm{Mg}$ content than the rotaliid species, and their biomineralization mechanisms are thought to be substantially different (Fig. 5). The fact that a higher F content corresponds to a higher $\mathrm{Mg}$ content may point towards a strong biological control on $\mathrm{F}$ incorporation. Fluorine may be incorporated in solid solutions. Fluorite $\left(\mathrm{CaF}_{2}\right)$ solid solution has been suggested as the incorporation mechanism for fluorine in calcite (Carpenter, 1969) but fluorapatite $\left(\mathrm{Ca}_{5}\left(\mathrm{PO}_{4}\right)_{3}(\mathrm{OH}, \mathrm{F})\right)$ solid solution would also be a possible option. Using spectroscopic techniques such as synchrotron could potentially identify the incorporation mode of $\mathrm{F}$ in foraminiferal calcite and, hence, whether fluorite or fluorapatite may play a role. This requires further investigations that are outside the scope of this study.

\section{2 $\mathrm{Cl}$ and $\mathrm{F}$ incorporation in foraminifera is primarily controlled by the biomineralization pathway}

In the two species of rotaliid foraminifera that were investigated here, $\mathrm{Cl}$ and $\mathrm{F}$ show strong banding. The $\mathrm{Cl}$ and $\mathrm{F}$ bands are co-located with $\mathrm{P}$ in the foraminiferal shell walls. As phosphorus is present in organic molecules like phospholipids in membranes, $\mathrm{P} / \mathrm{Ca}$ can be used to image organic linings in between the lamella in hyaline foraminiferal shell walls, as demonstrated in Geerken et al. (2019). Here, we use the term organic linings to refer collectively to the primary organic sheet and other organic linings in the shell wall. In A. tepida, the correlation of $\mathrm{Cl}$ and $\mathrm{F}$ with $\mathrm{P}$ is tight, and we conclude that both elements are primarily associated with the organic linings. In $A$. lessonii, the peaks in the $\mathrm{Cl} / \mathrm{Ca}$ and $\mathrm{F} / \mathrm{Ca}$ lateral profiles are also co-located with peaks in $\mathrm{P} / \mathrm{Ca}$. However, in the specimens that we analysed, there also seems to be substantial additional $\mathrm{Cl}$ and $\mathrm{F}$ in some calcite lamella, as can be seen in the lateral profiles. Moreover, the contrast between high-intensity bands and low-intensity bands is less prominent in A. lessonii than in A. tepida. We suggest that association with organic linings is also the primary mode of incorporation of both elements in the foraminiferal shells in A. lessonii. Using NanoSIMS and the very same species and specimens, Geerken et al. (2019) reported the co-occurrence of organic linings and banding of $\mathrm{Mg}, \mathrm{Na}, \mathrm{Sr}, \mathrm{K}, \mathrm{S}, \mathrm{P}$, and N. Moreover, they showed that elemental incorporation in $A$. lessonii was higher overall than in A. tepida, which is consistent with our observations for the halogens (Figs. 1, 2).
In the miliolids, the distributions of $\mathrm{Cl}$ and $\mathrm{F}$ are distinctly different from those of the rotaliids: as miliolids do not calcify by adding subsequent lamella of calcite (Fig. 5), no patterns of alternating high and low concentration banding are visible. Moreover, $\mathrm{Cl}$ and $\mathrm{F}$ are spatially not correlated throughout the shell walls of these miliolids, indicating that $\mathrm{Cl}$ and $\mathrm{F}$ may have different modes of incorporation. The correlation of $\mathrm{Cl}$ and $\mathrm{P}$ within the shell wall supports the hypothesis that $\mathrm{Cl}$ is incorporated in the calcite as a solid solution of chlorapatite, a mineral containing both $\mathrm{Cl}$ and $\mathrm{P}$, or associated with organic molecules as for the rotaliids but then distributed in a less organized way (no banding) within the calcite. The type of organics present in foraminiferal calcite is determined by the precipitation pathway: rotaliids initiate calcification around a primary organic sheet (POS) and cover their shell with organic linings, whereas miliolid shells are comprised of randomly oriented calcite needles held together in an organic matrix. As these organics may differ in their $\mathrm{P}$ content, it is possible to measure comparable $\mathrm{P}$ contents in both rotaliid and miliolid calcite, even though their absolute organic matter content within the calcite is expected to be different. Thus, similar $\mathrm{Cl}$ content in both rotaliids and miliolids may be due to differences in the composition of the organics or may hint at an incorporation via a different pathway. Alternatively, apatite may form via the adsorption of phosphate to calcite and amorphous calcium phosphates at low $\mathrm{Mg}$ concentrations in solution (Martens and Harriss, 1970; Millero et al., 2001). The incorporation of $\mathrm{Cl}$ via chlorapatite could also explain the spatial correlation of $\mathrm{Cl}$ and $\mathrm{P}$ in the species we analysed. If $\mathrm{F}$ were incorporated similarly to $\mathrm{Cl}$, we would expect the $\mathrm{F}$ and $\mathrm{Cl}$ distribution to be comparable. As this is not the case, we conclude that $\mathrm{F}$ is primarily incorporated in a different way than $\mathrm{Cl}$, e.g. as a solid solution of fluorite, as previously suggested (Rosenthal and Boyle, 1993).

The observed difference between F-rich miliolids lacking organic linings and clear banding of trace elements on the one hand, and the rotaliids with $\mathrm{F}-, \mathrm{Cl}-$, and P-rich bands on the other hand, is consistent with known differences in calcification mechanisms (Fig. 5) that have developed during the evolution of foraminifera (Debenay et al., 1996; Bentov and Erez, 2006). Hyaline (including the rotaliid) foraminifera precipitate calcite onto organic templates within an extracellular but confined space, and they add a new lamella to the entire shell each time they produce a new chamber (Hemleben et al., 1986; de Nooijer et al., 2014). For some intermediate-Mg calcite-producing foraminifera (like A. lobifera or A. lessonii), the transport of vesicles to the site of calcification has been observed, suggesting controlled biomineralization (at least partly) from internal $\mathrm{Ca}$ and carbonate pools (e.g. de Nooijer et al., 2009). Furthermore, in hyaline foraminifera, selective ion transport to the site of calcification via transmembrane pumping of elements is discussed as the biological control on biomineralization (Nehrke et al., 2013; de Nooijer et al., 2014; Toyofuku et al., 2017). In contrast, 

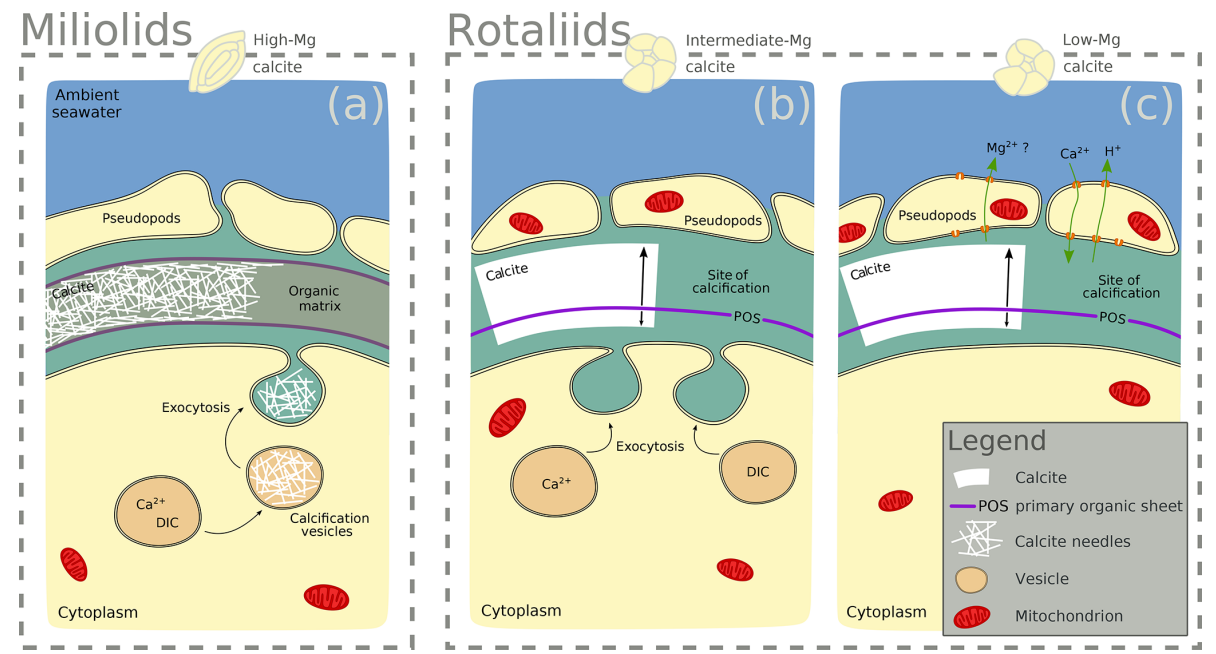

Figure 5. Scheme highlighting differences in the calcification mechanisms in miliolid and rotaliid foraminifera. Miliolid foraminifera precipitate calcium crystals in intracellular vesicles prior to arranging them in the shape of the new chamber wall (a; Angell, 1980; Hemleben et al., 1986; Debenay et al., 1996, 1998, 2000; Bentov and Erez, 2006). Rotaliid foraminifera precipitate calcite onto organic templates within an extracellular but confined space, and they add a new lamella to the entire shell each time they produce a new chamber (b, $\mathbf{c}$; Hemleben et al., 1986; de Nooijer et al., 2014). In intermediate-Mg calcite-producing rotaliid foraminifera (like A. lessonii), the transport of vesicles to the site of calcification has been observed, suggesting controlled biomineralization (at least partly) from internal Ca and carbonate pools (b; e.g. de Nooijer et al., 2009). In rotaliid low-Mg calcite-producing foraminifera, selective ion transport to the site of calcification via the transmembrane pumping of elements is discussed as the biological control on biomineralization (c; Nehrke et al., 2013; de Nooijer et al., 2014; Toyofuku et al., 2017).

porcelaneous miliolid foraminifera produce a wall of high$\mathrm{Mg}$ calcite with thin inner and outer layers connected by a thick middle layer of crystal needles (Hemleben et al., 1986; Debenay et al., 1996) that are glued together by an organic matrix. Miliolid foraminifera are generally thought to precipitate calcium crystals in intracellular vesicles prior to arranging them in the shape of the new chamber wall (Angell, 1980; Hemleben et al., 1986; Debenay et al., 1998, 2000; Bentov and Erez, 2006). Furthermore, there are species within the suborder of the miliolids that show features of both biomineralization pathways, such as Archaias angulatus, which appears to precipitate calcite at the site of the new chamber wall, opposed to other miliolid species (Wetmore, 1999).

During calcification, miliolids enclose seawater vesicles (Fig. 5) and then produce calcite that is rich in various cations (van Dijk et al., 2017, Table A1) and F (Fig. 1). The rotaliids such as A. tepida may use highly selective ion channels and organic layers to deposit new calcite. As a consequence, these calcites are low in $\mathrm{Mg}, \mathrm{Ba}$, and the halogens $(\mathrm{F}$ and $\mathrm{Cl})$ and show distinct banding. The rotaliid A. lessonii produces calcite with intermediate-Mg contents and less distinct banding for cations (Geerken et al., 2019), which is indicative of less biological control on ion transport and calcite deposition than in A. tepida. Our results for $\mathrm{P}, \mathrm{Cl}$, and $\mathrm{F}$ support this.

\section{Conclusions}

Here, we investigated, for the first time, the spatial distribution of the halogens $\mathrm{Cl}$ and $\mathrm{F}$ in foraminiferal shell walls. In the rotaliid benthic species Ammonia tepida and Amphistegina lessonii, $\mathrm{Cl}$ and $\mathrm{F}$ are distributed in bands within the chamber walls, which co-locate with P banding. In the miliolid benthic species Sorites marginalis and Archaias angulatus, $\mathrm{Cl}$ and $\mathrm{F}$ were not found to occur in bands. However, the rather homogeneously distributed $\mathrm{Cl}$ was found to correlate with $\mathrm{P}$ content, whereas $\mathrm{F}$ did not correlate with either $\mathrm{P}$ or $\mathrm{Cl}$. Based on these findings, we suggest that $\mathrm{Cl}$ and $\mathrm{F}$ are predominately associated with organic linings in the rotaliid species. We further propose that $\mathrm{Cl}$ may be incorporated in miliolid species as a solid solution of chlorapatite or be associated with organics. Our data in the miliolid species suggests that $\mathrm{F}$ is incorporated in a different way than $\mathrm{Cl}$, as $\mathrm{F}$ does not correlate with P. Further research is required to evaluate the potential of $\mathrm{Cl}$ and $\mathrm{F}$ in shells of benthic foraminifera for proxy applications. 


\section{Appendix A: Supplementary tables and figures}
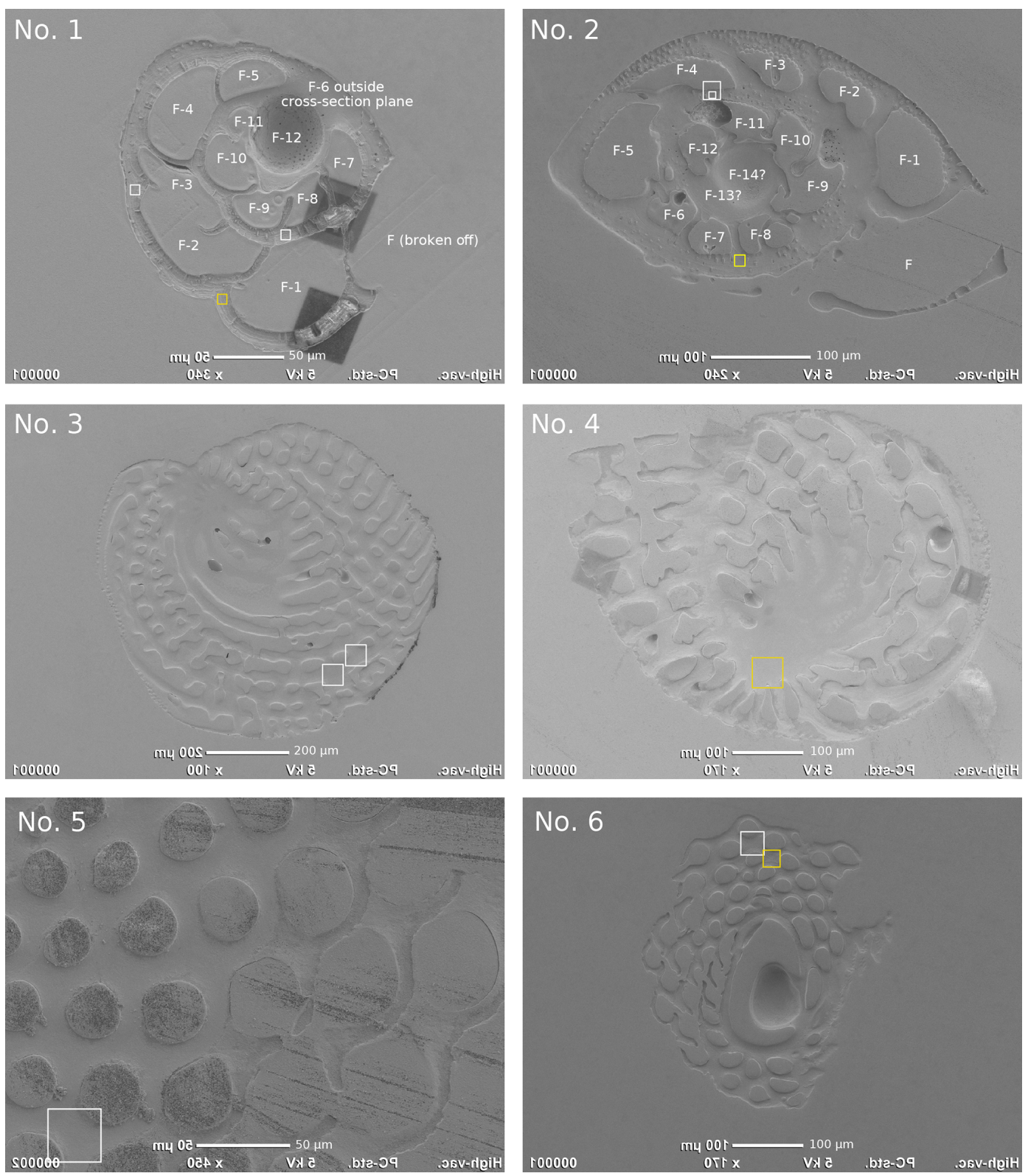

Figure A1. SEM images of the analysed specimens with the areas imaged by NanoSIMS indicated using white or yellow squares: Ammonia tepida (no. 1), Amphistegina lessonii (no. 2), Archaias angulatus (nos. 3 and 4), Sorites marginalis (nos. 5 and 6). The specimen numbers correspond to those in Tables 1 and A1. The yellow squares indicate the locations of the NanoSIMS images shown in Fig. 1. SEM images are flipped horizontally to facilitate navigation in the NanoSIMS instrument, where the secondary ion images are horizontally mirrored. 


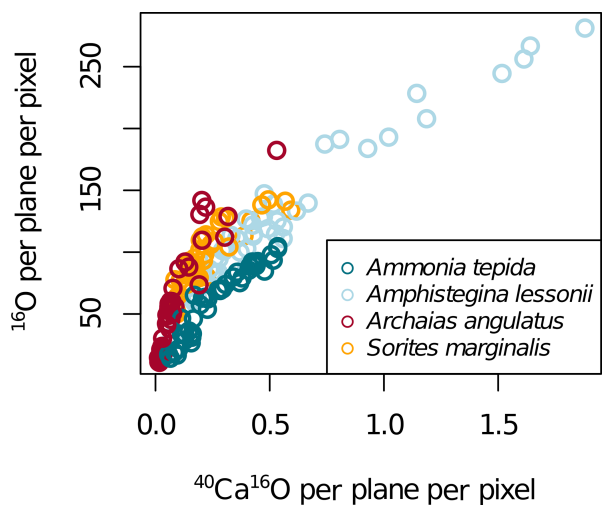

Figure A2. NanoSIMS ${ }^{40} \mathrm{Ca}^{16} \mathrm{O}$ per plane per pixel and ${ }^{16} \mathrm{O}$ per plane per pixel in four foraminifera species. The NanoSIMS ion count rates of ${ }^{40} \mathrm{Ca}^{16} \mathrm{O}$ and ${ }^{16} \mathrm{O}$ highly correlated in calcite (Fig. A2), which is why elemental ratios can be normalized to both for display. As elemental ratios determined in bulk calcite are normalized to calcium, we present the NanoSIMS data mostly as $\mathrm{El} /{ }^{40} \mathrm{Ca}{ }^{16} \mathrm{O}$ ion count ratios.

Ammonia tepida, $\mathrm{n}=40$

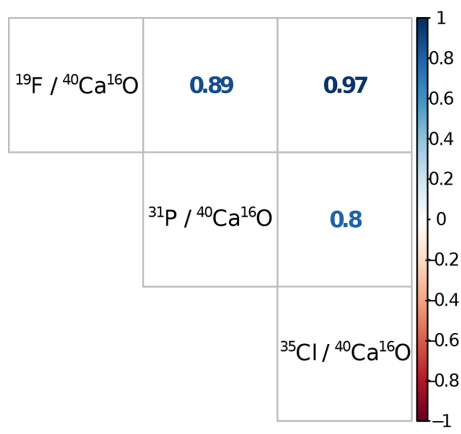

Archaias angulatus, $\mathrm{n}=46$

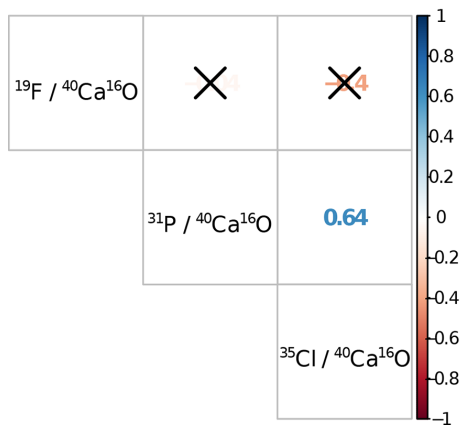

Amphistegina lessonii, $\mathrm{n}=47$

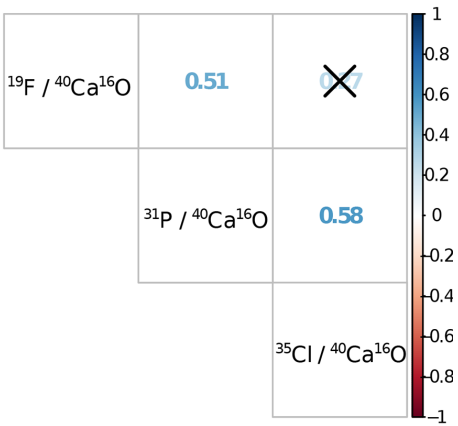

Sorites marginalis, $\mathrm{n}=45$

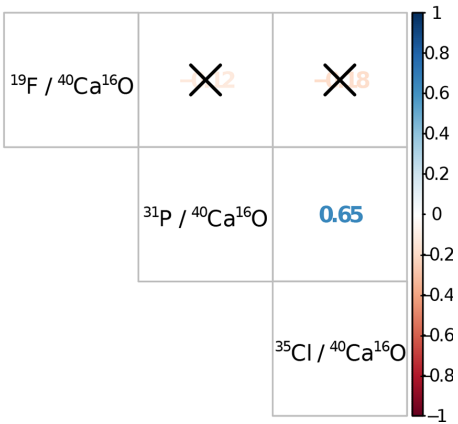

Figure A3. Correlation matrices of NanoSIMS ${ }^{19} \mathrm{~F} /{ }^{40} \mathrm{Ca}^{16} \mathrm{O},{ }^{31} \mathrm{P} /{ }^{40} \mathrm{Ca}^{16} \mathrm{O}$, and ${ }^{35} \mathrm{Cl} /{ }^{40} \mathrm{Ca}{ }^{16} \mathrm{O}$ ion count ratios per foraminiferal species across $n$ ROIs. Coloured numbers in the matrix are the $R^{2}$ values, and the correlation is significant at the $p<0.001$ level when no black cross is present. The plot was created using the corrplot package in R (Wei and Simko, 2017; R Core Team, 2018). 

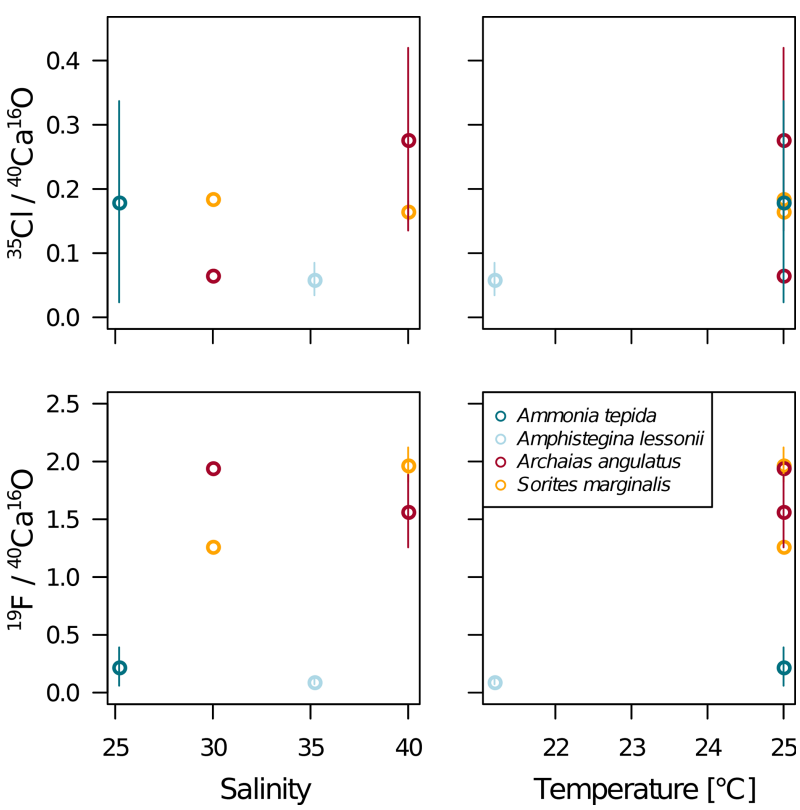

Figure A4. NanoSIMS ${ }^{35} \mathrm{Cl} /{ }^{40} \mathrm{Ca}^{16} \mathrm{O}$ and ${ }^{19} \mathrm{~F} /{ }^{40} \mathrm{Ca}^{16} \mathrm{O}$ ion count ratios in the measured specimens versus temperature and salinity of the culture media. The error bars depict the standard deviation of the mean NanoSIMS ion count ratios for those specimens where more than one image was analysed on the shell.
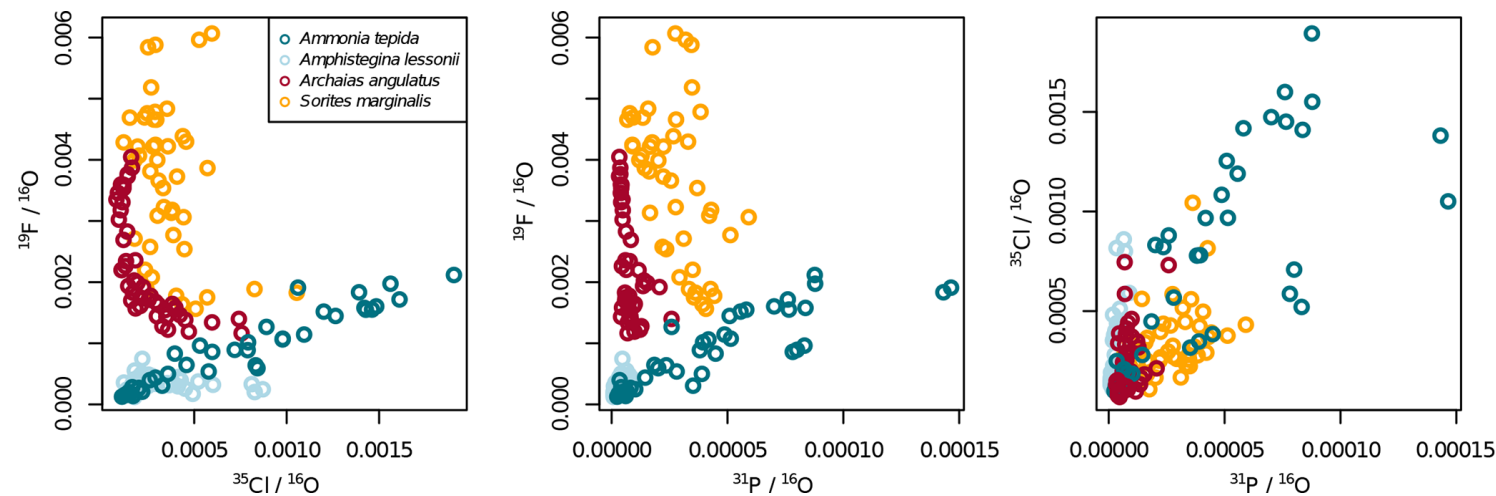

Figure A5. Illustration to show that the patterns in Fig. 2 do not change much when normalizing to ${ }^{16} \mathrm{O}$ instead of ${ }^{40} \mathrm{Ca}{ }^{16} \mathrm{O}$. 

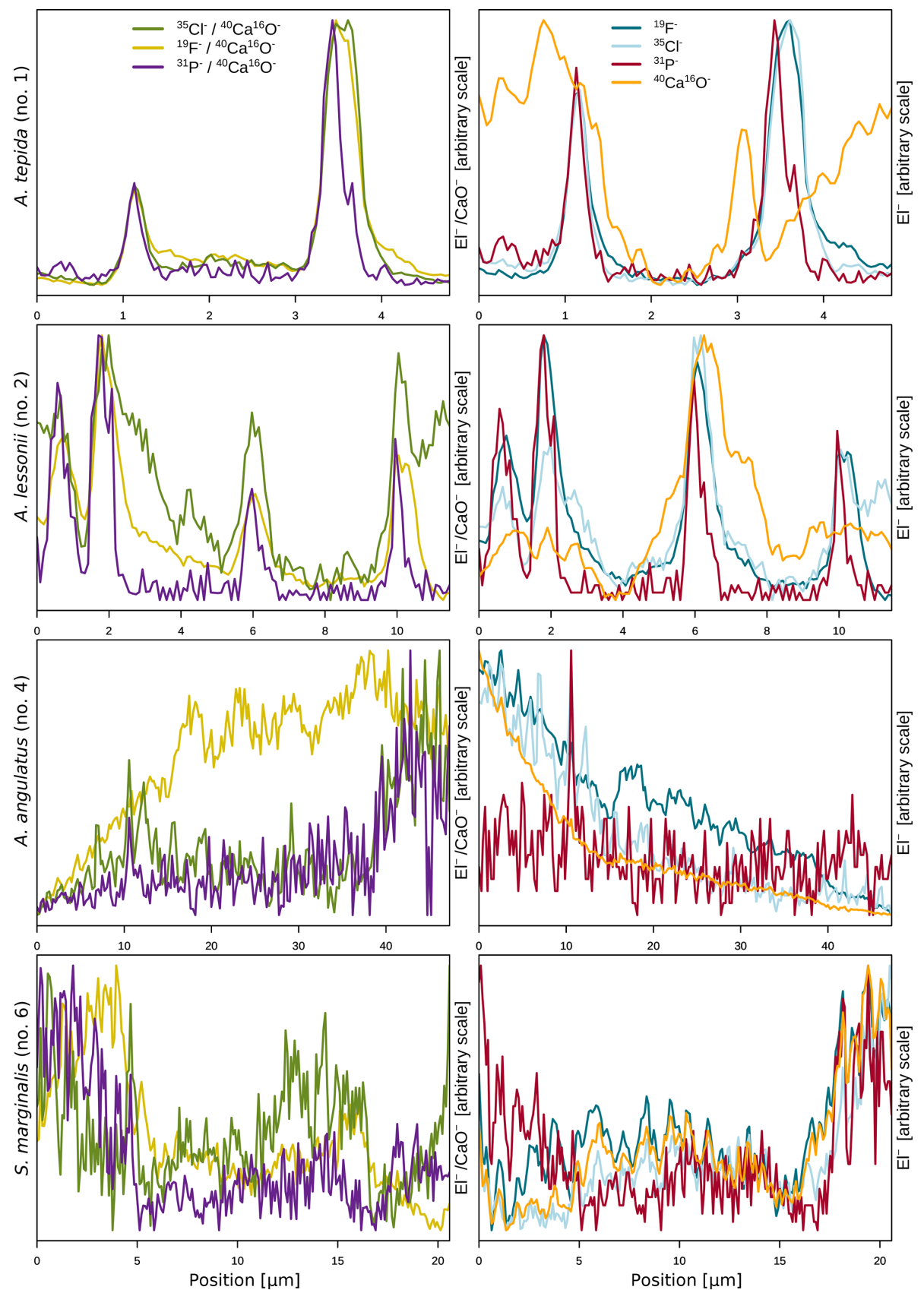

Figure A6. Illustration to show that the banding pattern seen in the lateral profiles of the rotaliid species in Fig. 1 is not caused by lower Ca ion counts at the position of organic linings. The left panels show the same lateral profiles of the El/Ca ion count ratios as shown in Fig. 1, whereas the right panels show the distribution of the individual elements (shown as ion counts) along the same lateral profile. 
Table A1. Additional information on specimens. LA-ICP-MS data of average single shell El/Ca ratios were determined on several chambers.

\begin{tabular}{llllrrrrr}
\hline No. & Specimen ID* & Species & Symbionts & $\begin{array}{r}\mathrm{Na} / \mathrm{Ca} \\
\left(\mathrm{mmol} \mathrm{mol}^{-1}\right)\end{array}$ & $\begin{array}{r}\mathrm{Mg} / \mathrm{Ca} \\
\left(\mathrm{mmol} \mathrm{mol}^{-1}\right)\end{array}$ & $\begin{array}{r}\mathrm{Sr} / \mathrm{Ca} \\
\left(\mathrm{mmol} \mathrm{mol}^{-1}\right)\end{array}$ & $\begin{array}{r}\mathrm{Al} / \mathrm{Ca} \\
\left(\mathrm{mmol} \mathrm{mol}^{-1}\right)\end{array}$ \\
$\left(\mathrm{mmol} \mathrm{mol}^{-1}\right)$
\end{tabular}

* Lab internal specimen ID based on stub\#_number. For A. tepida as in Geerken et al. (2018).

Table A2. NanoSIMS 50L acquisition settings.

\begin{tabular}{|c|c|c|c|c|}
\hline NanoSIMS settings* & Ammonia tepida & Amphistegina lessonii & Archaias angulatus & Sorites marginalis \\
\hline \multicolumn{5}{|l|}{ Pre-sputtering } \\
\hline Beam current (in $\mathrm{FC}_{\mathrm{o}}$ ) (pA) & $\begin{array}{l}\sim 140 \\
\text { (preset } 10 \text { in D1-3) }\end{array}$ & $\begin{array}{l}\sim 280 \\
(\text { preset } 20 \text { in D1-3) }\end{array}$ & $\begin{array}{l}\sim 280 \\
\text { (preset } 20 \text { in D1-3) }\end{array}$ & $\begin{array}{l}\sim 140-280 \\
(\text { preset } 10-20 \text { in D1-3) }\end{array}$ \\
\hline Diaphragm and slits & D1-1 & D1-1 & D1-1 & D1-1 \\
\hline $\mathrm{FOV}\left(\mu \mathrm{m}^{2}\right)$ & $8 \times 8$ & $12 \times 12$ to $23 \times 23$ & $55 \times 55$ & $25 \times 25$ to $40 \times 40$ \\
\hline Time (min) & 10 & 10 & 15 & $10-15$ \\
\hline eGun & On & On & On & On \\
\hline \multicolumn{5}{|l|}{ Image acquisition } \\
\hline Beam current (in $\left.\mathrm{FC}_{\mathrm{o}}\right)(\mathrm{pA})$ & 0.5 & 1 & 2 & 1 \\
\hline Diaphragm and slits & D1-3, ES-3, & D1-3, ES-3, & D1-3, ES-3, & D1-3, ES-3, \\
\hline Detected masses & $\begin{array}{l}\text { AS-2, EnS-1 } \\
{ }^{12} \mathrm{C},{ }^{16} \mathrm{O},{ }^{19} \mathrm{~F},{ }^{31} \mathrm{P} \\
{ }^{35} \mathrm{Cl},{ }^{37} \mathrm{Cl},{ }^{40} \mathrm{Ca}{ }^{16} \mathrm{O}\end{array}$ & $\begin{array}{l}\mathrm{AS}-2, \mathrm{EnS}-1 \\
{ }^{12} \mathrm{C},{ }^{16} \mathrm{O},{ }^{19} \mathrm{~F},{ }^{31} \mathrm{P} \\
{ }^{35} \mathrm{Cl},{ }^{37} \mathrm{Cl},{ }^{40} \mathrm{Ca}^{16} \mathrm{O}\end{array}$ & $\begin{array}{l}\mathrm{AS}-2, \mathrm{EnS}-1 \\
{ }^{12} \mathrm{C},{ }^{16} \mathrm{O},{ }^{19} \mathrm{~F},{ }^{31} \mathrm{P} \\
{ }^{35} \mathrm{Cl},{ }^{37} \mathrm{Cl},{ }^{40} \mathrm{Ca}{ }^{16} \mathrm{O}\end{array}$ & $\begin{array}{l}\mathrm{AS}-2, \mathrm{EnS}-1 \\
{ }^{12} \mathrm{C},{ }^{16} \mathrm{O},{ }^{19} \mathrm{~F},{ }^{31} \mathrm{P}, \\
{ }^{35} \mathrm{Cl},{ }^{37} \mathrm{Cl},{ }^{40} \mathrm{Ca}^{16} \mathrm{O}\end{array}$ \\
\hline Dwell time $\left(\mu \mathrm{px}^{-1}\right)$ & 1000 & 1000 & 1000 & 1000 \\
\hline Image FOV $\left(\mu \mathrm{m}^{2}\right)$ & $6 \times 6$ & $8 \times 8$ to $20 \times 20$ & $50 \times 50$ & $23 \times 23$ to $30 \times 30$ \\
\hline Image resolution $(\mathrm{px} \times \mathrm{px})$ & $128 \times 128$ & $128 \times 128$, once $256 \times 256$ & $256 \times 256$ & $256 \times 256$ \\
\hline Number of planes & 1000 & 1000 , once 250 & 250 & 250 \\
\hline eGun & On & On & On & On \\
\hline
\end{tabular}

* Abbreviations: objective current $\left(\mathrm{FC}_{\mathrm{o}}\right)$; field of view (FOV); electron flood gun (eGun). 
Data availability. The data presented in this study are available at https://doi.org/10.4121/uuid:9951e801-5574-498e-b375fa6941a0f071 (Roepert, 2019b).

Author contributions. JJM, GJR, and AR designed the experiments. EG prepared the samples for NanoSIMS analyses. EG and AR conducted the SEM analyses. AR conducted the NanoSIMS analyses. AR and LP performed the data analysis. AR interpreted the data, prepared the figures, and wrote the paper with contributions from all authors.

Competing interests. The authors declare that they have no conflict of interest.

Acknowledgements. We thank Inge van Dijk and two anonymous reviewers for their constructive feedback, which helped improve this work. We thank Inge van Dijk and Lennart de Nooijer for providing A. lessonii specimens and Michiel Kienhuis for analytical support. The NanoSIMS facility at Utrecht University was financed through a large infrastructure grant from the Netherlands Organisation for Scientific Research (NWO; grant no. 175.010.2009.011). This work was carried out in the framework of a Netherlands Earth System Science Centre (NESSC) programme, which was financially supported by the Ministry of Education, Culture and Science (OCW; grant no. 024.002.001).

Financial support. This research has been supported by the Netherlands Organisation for Scientific Research (NWO; grant no. 175.010.2009.011) and the Ministry of Education, Culture and Science (OCW), Netherlands (grant no. 024.002.001).

Review statement. This paper was edited by Aldo Shemesh and reviewed by two anonymous referees.

\section{References}

Allen, K. A., Hönisch, B., Eggins, S. M., Haynes, L. L., Rosenthal, Y., and Yu, J.: Trace element proxies for surface ocean conditions: A synthesis of culture calibrations with planktic foraminifera, Geochim. Cosmochim. Ac., 193, 197-221, 2016.

Angell, R. W.: Test morphogenesis (chamber formation) in the foraminifer Spiroloculina hyalina Schulze, J. Foramin. Res., 10, 89-101, 1980.

Barker, S., Greaves, M., and Elderfield, H.: A study of cleaning procedures used for foraminiferal $\mathrm{Mg} / \mathrm{Ca}$ paleothermometry, Geochem. Geophy. Geosy., 4, 8407, https://doi.org/10.1029/2003GC000559, 2003.

Bentov, S. and Erez, J.: Impact of biomineralization processes on the $\mathrm{Mg}$ content of foraminiferal shells: A biological perspective, Geochem. Geophy. Geosy., 7, Q01P08, https://doi.org/10.1029/2005GC001015, 2006
Bonnin, E. A., Zhu, Z., Fehrenbacher, J. S., Russell, A. D., Hönisch, B., Spero, H. J., and Gagnon, A. C.: Submicron Sodium Banding in Cultured Planktic Foraminifera Shells, Geochim. Cosmochim. Ac., 253, 127-141, https://doi.org/10.1016/j.gca.2019.03.024, 2019.

Boyle, E. A.: Cadmium, zinc, copper, and barium in foraminifera tests, Earth Planet. Sc. Lett., 53, 11-35, https://doi.org/10.1016/0012-821X(81)90022-4, 1981.

Branson, O., Kaczmarek, K., Redfern, S. A., Misra, S., Langer, G., Tyliszczak, T., Bijma, J., and Elderfield, H.: The coordination and distribution of B in foraminiferal calcite, Earth Planet. Sc Lett., 416, 67-72, 2015.

Branson, O., Bonnin, E. A., Perea, D. E., Spero, H. J., Zhu, Z., Winters, M., Hönisch, B., Russell, A. D., Fehrenbacher, J. S., and Gagnon, A. C.: Nanometer-scale chemistry of a calcite biomineralization template: Implications for skeletal composition and nucleation, P. Natl. Acad. Sci. USA, 113, 12934-12939, 2016.

Carpenter, R.: Factors controlling the marine geochemistry of fluorine, Geochim. Cosmochim. Ac., 33, 1153-1167, https://doi.org/10.1016/0016-7037(69)90038-6, 1969.

Debenay, J.-P., Guillou, J.-J., and Lesourd, M.: Colloidal calcite in foraminiferal tests; crystallization and texture of the test, J. Foramin. Res., 26, 277-288, 1996.

Debenay, J.-P., Guillou, J.-J., Geslin, E., Lesourd, M., and Redois, F.: Processus de cristallisation de plaquettes rhomboédriques à la surface d'un test porcelané de foraminifère actuel, Geobios, 31, 295-302, 1998.

Debenay, J.-P., Guillou, J.-J., Geslin, E., and Lesourd, M.: Crystallization of calcite in foraminiferal tests, Micropaleontology, 46, 87-94, 2000

de Nooijer, L. J., Toyofuku, T., and Kitazato, H.: Foraminifera promote calcification by elevating their intracellular $\mathrm{pH}, \mathrm{P}$. Natl. Acad. Sci. USA, 106, 15374-15378, 2009.

de Nooijer, L. J., Spero, H. J., Erez, J., Bijma, J., and Reichart, G. J.: Biomineralization in perforate foraminifera, Earth-Sci. Rev., 135, 48-58, 2014.

Eggins, S. M., Sadekov, A., and De Deckker, P.: Modulation and daily banding of $\mathrm{Mg} / \mathrm{Ca}$ in Orbulina universa tests by symbiont photosynthesis and respiration: a complication for seawater thermometry?, Earth Planet. Sc. Lett., 225, 411-419, 2004.

Elderfield, H., Bertram, C., and Erez, J.: A biomineralization model for the incorporation of trace elements into foraminiferal calcium carbonate, Earth Planet. Sc. Lett., 142, 409-423, 1996.

Erez, J.: The source of ions for biomineralization in foraminifera and their implications for paleoceanographic proxies, Rev. Mineral. Geochem., 54, 115-149, 2003.

Evans, D., Erez, J., Oron, S., and Müller, W.: Mg/Ca-temperature and seawater-test chemistry relationships in the shallow-dwelling large benthic foraminifera Operculina ammonoides, Geochim. Cosmochim. Ac., 148, 325-342, 2015.

Fehrenbacher, J. S., Russell, A. D., Davis, C. V., Gagnon, A. C., Spero, H. J., Cliff, J. B., Zhu, Z., and Martin, P.: Link between light-triggered $\mathrm{Mg}$-banding and chamber formation in the planktic foraminifera Neogloboquadrina dutertrei, Nat. Commun., 8, 15441, 2017.

Gattuso, J.-P., Epitalon, J.-M., Lavigne, H., and Orr, J.: seacarb: Seawater Carbonate Chemistry, $r$ package version 3.2.10, available at: https://CRAN.R-project.org/package=seacarb, last access: 10 November 2018. 
Geerken, E., de Nooijer, L. J., van Dijk, I., and Reichart, G.J.: Impact of salinity on element incorporation in two benthic foraminiferal species with contrasting magnesium contents, Biogeosciences, 15, 2205-2218, https://doi.org/10.5194/bg-152205-2018, 2018.

Geerken, E., de Nooijer, L. J., Roepert, A., Polerecky, L., King, H. E., and Reichart, G.-J.: Element banding and organic linings within chamber walls of two benthic foraminifera, Sci. Rep.-UK, 9, 3598, https://doi.org/10.1038/s41598-019-40298-y, 2019.

Glock, N., Liebetrau, V., Vogts, A., and Eisenhauer, A.: Organic Heterogeneities in Foraminiferal Calcite Traced Through the Distribution of N, S, and I Measured With NanoSIMS: A New Challenge for Element-Ratio-Based Paleoproxies?, Front. Earth Sci., 7, 175, https://doi.org/10.3389/feart.2019.00175, 2019.

Hemleben, C., Erson, O., Berthold, W., and Spindler, M.: Calcification and chamber formation in Foraminifera - a brief overview, in: Biomineralization in lower plants and animals, edited by: Leadbeater, B. S. C. and Riding, R., Clarendon Press, Oxford, 237-249, 1986.

Ichikuni, M.: Uptake of fluoride by aragonite, Chem. Geol., 27, 207-214, https://doi.org/10.1016/0009-2541(79)90039-1, 1979.

Jonkers, L., Buse, B., Brummer, G.-J. A., and Hall, I. R.: Chamber formation leads to $\mathrm{Mg} / \mathrm{Ca}$ banding in the planktonic foraminifer Neogloboquadrina pachyderma, Earth Planet. Sc. Lett., 451, 177-184, 2016.

Kendrick, M. A.: Halogens in seawater, marine sediments and the altered oceanic lithosphere, in: The role of halogens in terrestrial and extraterrestrial geochemical processes, edited by: Harlov, D. E. and Aranovich, L., 591-648, https://doi.org/10.1007/978-3319-61667-4_9, Springer International Publishing, Cham, 2018.

Kitano, Y., Okumura, M., and Idogaki, M.: Incorporation of sodium, chloride and sulfate with calcium carbonate, Geochem. J., 9, 7584, 1975.

Kunioka, D., Shirai, K., Takahata, N., Sano, Y., Toyofuku, T., and Ujiie, Y.: Microdistribution of $\mathrm{Mg} / \mathrm{Ca}, \mathrm{Sr} / \mathrm{Ca}$, and $\mathrm{Ba} / \mathrm{Ca}$ ratios in Pulleniatina obliquiloculata test by using a NanoSIMS: Implication for the vital effect mechanism, Geochem. Geophy. Geosy., 7, 12, https://doi.org/10.1029/2006GC001280, 2006.

Lea, D. W., Mashiotta, T. A., and Spero, H. J.: Controls on magnesium and strontium uptake in planktonic foraminifera determined by live culturing, Geochim. Cosmochim. Ac., 63, 2369-2379, 1999.

Lee, K., Tong, L. T., Millero, F. J., Sabine, C. L., Dickson, A. G., Goyet, C., Park, G.-H., Wanninkhof, R., Feely, R. A., and Key, R. M.: Global relationships of total alkalinity with salinity and temperature in surface waters of the world's oceans, Geophys. Res. Lett., 33, L19605, https://doi.org/10.1029/2006GL027207, 2006.

Lu, Z., Jenkyns, H. C., and Rickaby, R. E.: Iodine to calcium ratios in marine carbonate as a paleo-redox proxy during oceanic anoxic events, Geology, 38, 1107-1110, 2010.

Lueker, T. J., Dickson, A. G., and Keeling, C. D.: Ocean $p \mathrm{CO}_{2}$ calculated from dissolved inorganic carbon, alkalinity, and equations for $\mathrm{K} 1$ and $\mathrm{K} 2$ : validation based on laboratory measurements of $p \mathrm{CO}_{2}$ in gas and seawater at equilibrium, Mar. Chem., 70, 105-119, 2000.

Martens, C. S. and Harriss, R. C.: Inhibition of apatite precipitation in the marine environment by magnesium ions, Geochim. Cosmochim. Ac., 34, 621-625, 1970.
Mezger, E. M., de Nooijer, L. J., Bertlich, J., Bijma, J., Nürnberg, D., and Reichart, G.-J.: Planktonic foraminiferal spine versus shell carbonate $\mathrm{Na}$ incorporation in relation to salinity, Biogeosciences, 16, 1147-1165, https://doi.org/10.5194/bg-161147-2019, 2019.

Millero, F., Huang, F., Zhu, X., Liu, X., and Zhang, J.-Z.: Adsorption and desorption of phosphate on calcite and aragonite in seawater, Aquat. Geochem., 7, 33-56, 2001.

Nehrke, G., Keul, N., Langer, G., de Nooijer, L. J., Bijma, J., and Meibom, A.: A new model for biomineralization and traceelement signatures of Foraminifera tests, Biogeosciences, 10, 6759-6767, https://doi.org/10.5194/bg-10-6759-2013, 2013.

Okumura, M., Kitano, Y., and Idogaki, M.: Incorporation of fluoride ions into calcite-Effect of organic materials and magnesium ions in a parent solution, Geochem. J., 17, 257-263, https://doi.org/10.2343/geochemj.17.257, 1983.

Okumura, M., Kitano, Y., and Idogaki, M.: Behavior of bromide ions during the formation of calcium carbonate, Mar. Chem., 19, 109-120, 1986.

Opdyke, B. N., Walter, L. M., and Huston, T. J.: Fluoride content of foraminiferal calcite: Relations to life habitat, oxygen isotope composition, and minor element chemistry, Geology, 21, 169172, 1993.

Paris, G., Fehrenbacher, J. S., Sessions, A. L., Spero, H. J., and Adkins, J. F.: Experimental determination of carbonate-associated sulfate $\delta^{34} \mathrm{~S}$ in planktonic foraminifera shells, Geochem. Geophy. Geosy., 15, 1452-1461, 2014.

Polerecky, L., Adam, B., Milucka, J., Musat, N., Vagner, T., and Kuypers, M. M.: Look@NanoSIMS - a tool for the analysis of nanoSIMS data in environmental microbiology, Environ. Microbiol., 14, 1009-1023, 2012.

Rae, J. W. B., Foster, G. L., Schmidt, D. N., and Elliott, T.: Boron isotopes and $\mathrm{B} / \mathrm{Ca}$ in benthic foraminifera: Proxies for the deep ocean carbonate system, Earth Planet. Sc. Lett., 302, 403-413, 2011.

R Core Team: R: A Language and Environment for Statistical Computing, R Foundation for Statistical Computing, Vienna, Austria, available at: https://www.R-project.org/, last access: 10 November 2018 .

Roepert, A.: Imaging element distributions within small marine calcifiers: a NanoSIMS perspective, PhD Thesis, Utrecht Studies in Earth Sciences, Vol. 201, 232 pp., 2019a.

Roepert, A.: Supplementary data to "Distribution of $\mathrm{Cl}$ and $\mathrm{F}$ in benthic foraminifera", 4TU.ResearchData, Dataset, https://doi.org/10.4121/uuid:9951e801-5574-498e-b375fa6941a0f071, 2019b.

Rosenthal, Y. and Boyle, E. A.: Factors controlling the fluoride content of planktonic foraminifera: An evaluation of its paleoceanographic applicability, Geochim. Cosmochim. Ac., 57, 335-346, 1993.

Rosenthal, Y., Boyle, E. A., and Slowey, N.: Temperature control on the incorporation of magnesium, strontium, fluorine, and cadmium into benthic foraminiferal shells from Little Bahama Bank: Prospects for thermocline paleoceanography, Geochim. Cosmochim. Ac., 61, 3633-3643, https://doi.org/10.1016/S00167037(97)00181-6, 1997.

Rude, P. D. and Aller, R. C.: Fluorine mobility during early diagenesis of carbonate sediment: An indicator of mineral 
transformations, Geochim. Cosmochim. Ac., 55, 2491-2509, https://doi.org/10.1016/0016-7037(91)90368-F, 1991.

Sadekov, A. Y., Eggins, S. M., and de Deckker, P.: Characterization of $\mathrm{Mg} / \mathrm{Ca}$ distributions in planktonic foraminifera species by electron microprobe mapping, Geochem. Geophy. Geosy., 6, 12, https://doi.org/10.1029/2005GC000973, 2005.

Spero, H. J., Eggins, S. M., Russell, A. D., Vetter, L., Kilburn, M. R., and Hönisch, B.: Timing and mechanism for intratest $\mathrm{Mg} / \mathrm{Ca}$ variability in a living planktic foraminifer, Earth Planet. Sc. Lett., 409, 32-42, 2015.

Szafranek, D. and Erez, J.: Chemistry of $\mathrm{Mg}, \mathrm{SO}_{4}^{2-}, \mathrm{Sr}, \mathrm{Na}$, and $\mathrm{Cl}$ in live foraminifera shells, in: The 7th International Symp. on Biomineralization, Monaco, Program and Abstracts, 1993.

Tanaka, K., Ono, T., Fujioka, Y., and Ohde, S.: Fluoride in nonsymbiotic coral associated with seawater carbonate, Mar. Chem., 149, 45-50, 2013.

Tokuyama, A., Kitano, Y., and Kaneshima, K.: Geochemical behavior of chemical species in the processes of limestone formation. Part I. Chemical composition of corals and limestones in the Ryukyu Islands, Geochem. J., 6, 83-92, 1972.

Toyofuku, T., Matsuo, M. Y., de Nooijer, L. J., Nagai, Y., Kawada, S., Fujita, K., Reichart, G.-J., Nomaki, H., Tsuchiya, M., Sakaguchi, H., and Kitazato, H.: Proton pumping accompanies calcification in foraminifera, Nat. Commun., 8, 14145, https://doi.org/10.1038/ncomms14145, 2017. van Dijk, I., de Nooijer, L. J., and Reichart, G.-J.: Trends in element incorporation in hyaline and porcelaneous foraminifera as a function of $p \mathrm{CO}_{2}$, Biogeosciences, 14, 497-510, https://doi.org/10.5194/bg-14-497-2017, 2017.

van Dijk, I., Barras, C., de Nooijer, L. J., Mouret, A., Geerken, E., Oron, S., and Reichart, G.-J.: Coupled calcium and inorganic carbon uptake suggested by magnesium and sulfur incorporation in foraminiferal calcite, Biogeosciences, 16, 2115-2130, https://doi.org/10.5194/bg-16-2115-2019, 2019.

Wei, T. and Simko, V.: R package "corrplot": Visualization of a Correlation Matrix, Version 0.84, available at: https://github.com/ taiyun/corrplot (last access: 12 November 2018), 2017.

Wetmore, K. L.: Chamber formation in Archaias angulatus, The J. Foramin. Res., 29, 69-74, 1999.

Wit, J. C., de Nooijer, L. J., Wolthers, M., and Reichart, G. J.: A novel salinity proxy based on $\mathrm{Na}$ incorporation into foraminiferal calcite, Biogeosciences, 10, 6375-6387, https://doi.org/10.5194/bg-10-6375-2013, 2013.

Yu, J., Elderfield, H., and Hönisch, B.: B/Ca in planktonic foraminifera as a proxy for surface seawater $\mathrm{pH}$, Paleoceanography, 22, 2, https://doi.org/10.1029/2006PA001347, 2007. 